\title{
SEHR-ECHO v1.0: a Spatially Explicit Hydrologic Response model for ecohydrologic applications
}

\author{
B. Schaefli ${ }^{1}$, L. Nicótina ${ }^{2}$, C. Imfeld ${ }^{1, *}$, P. Da Ronco ${ }^{1,3, * *, * * *}$, E. Bertuzzo ${ }^{1}$, and A. Rinaldo ${ }^{1,3}$ \\ ${ }^{1}$ Laboratory of Ecohydrology, School of Architecture, Civil and Environmental Engineering (ENAC), \\ Ecole Polytechnique Fédérale de Lausanne (EPFL), Switzerland \\ ${ }^{2}$ Risk Management Solutions Ltd., London, UK \\ ${ }^{3}$ Dipartimento di Ingegneria Civile, Edile e Ambientale (ICEA), Università di Padova, Padua, Italy \\ *now at: Hollinger Engineering, Ecublens, Switzerland \\ ** now at: Impacts on Soil and Coasts Division, Euro-Mediterranean Center for Climate Change, \\ Capua (CE), Italy \\ ****now at: Department of Civil and Environmental Engineering - Politecnico di Milano, \\ Milan, Italy
}

Correspondence to: B. Schaefli (bettina.schaefli@epfl.ch)

Received: 28 January 2014 - Published in Geosci. Model Dev. Discuss.: 19 March 2014

Revised: 8 October 2014 - Accepted: 13 October 2014 - Published: 20 November 2014

\begin{abstract}
This paper presents the Spatially Explicit Hydrologic Response (SEHR) model developed at the Laboratory of Ecohydrology of the Ecole Polytechnique Fédérale de Lausanne for the simulation of hydrological processes at the catchment scale. The key concept of the model is the formulation of water transport by geomorphologic travel time distributions through gravity-driven transitions among geomorphic states: the mobilization of water (and possibly dissolved solutes) is simulated at the subcatchment scale and the resulting responses are convolved with the travel paths distribution within the river network to obtain the hydrologic response at the catchment outlet. The model thus breaks down the complexity of the hydrologic response into an explicit geomorphological combination of dominant spatial patterns of precipitation input and of hydrologic process controls. Nonstationarity and nonlinearity effects are tackled through soil moisture dynamics in the active soil layer. We present here the basic model set-up for precipitation-runoff simulation and a detailed discussion of its parameter estimation and of its performance for the Dischma River (Switzerland), a snow-dominated catchment with a small glacier cover.
\end{abstract}

\section{Introduction}

Hydrological processes result from natural processes that vary strongly in space, such as precipitation, evaporation or infiltration into the subsoil (McDonnell et al., 2007; Beven, 2012). Accordingly, most state-of-the art hydrologic response models have two fundamental components to describe the arrival of water and transported substances at a control section: a component to simulate the temporal evolution of water storage (and possibly of energy or of solutes) and released fluxes in some hydrologically meaningful sub-units and a component to describe the transport of the fluxes between the sub-units along the river network, (e.g. Hingray et al., 2010; Clark et al., 2008; Kunstmann and Stadler, 2005). There are, however, many models without an explicit description of the water flow within the landscape and the river network. This transport component is either completely omitted as in lumped models (Perrin et al., 2003; Merz and Blöschl, 2004), assumed to be negligible at the spatio-temporal scale of interest (Viviroli et al., 2009; Schaefli et al., 2005), or assumed to fall out of the sum of transport processes simulated between small spatial units, without further parameterizing flow in channels (e.g. Tague and Band, 2001; Wigmosta et al., 1994; Liu and Todini, 2002). 
Some models use an arbitrary (calibrated) discharge routing function to smooth the response computed at the scale of a (sub-)catchment, e.g. with a triangular function as in the HBV model (Bergström, 1995) and derivations thereof (Wrede et al., 2013; Das et al., 2008). Finally, there exist models that can be thought of as having an implicit routing component (Tague and Band, 2001) even if they are applied in a completely lumped manner, i.e. a component that accounts statistically for spatial differences of runoff generation, such as Hymod (Boyle, 2000; Moradkhani et al., 2005) or the well-known Topmodel with its topographical wetness index (Beven and Kirkby, 1979) (which is, however, generally not applied in a lumped manner).

Most existing catchment-scale model applications show an explicit parameterization of channelled flow only for the largest rivers in the analysed system, for which typically a kinematic wave-based routing is used, assuming that at the subcatchment level, the effect of travel times in channels are negligible at the considered spatio-temporal resolution. This might typically hold for hourly discharge simulation with subcatchments of a few $10-100 \mathrm{~km}^{2}$ in reasonably steep environments (e.g. Hingray et al., 2010). For an example including subcatchment routing parameterization see, e.g., the work of Clark et al. (2008).

Traditionally, the range of aforementioned hydrological models is classified into (semi-)lumped and (semi)distributed (Reed et al., 2004; Beven, 2012), a classification which refers essentially to the parameterization of the temporal evolution of the water storage within the catchment. The terms distributed or semi-distributed (e.g. Das et al., 2008) generally refer to grid-based models or subcatchment set-ups with different parameter sets for each spatial unit, whereas semi-lumped implies some degree of spatial discretization but with a single parameter set and generally without flow routing through the landscape (e.g. Schaefli et al., 2005). Although not directly related, it is often implied that distributed models are more physics-based.

We propose the term of a spatially explicit hydrologic response (SEHR) model for any model that explicitly parameterizes both, spatial patterns of water storage evolution as well as the effect of geomorphology on the travel time of water having different spatial origins. We believe that the term spatially-explicit is more generic than the often used terms semi-lumped, semi-distributed or distributed model, which refer to specific set-ups in terms of spatial variability of state variables and of parameters.

Hereafter, we describe a simple catchment-scale hydrologic model developed at the Laboratory of Ecohydrology (ECHO) of the Ecole Polytechnique Fédérale de Lausanne, SEHR-ECHO, that explicitly accounts for the spatial variabilities in the runoff generation process and the heterogeneity of the flow-paths within the catchment. The model builds on the geomorphic theory of the hydrologic response (Rodriguez-Iturbe and Valdés, 1979; Rodriguez-Iturbe and Rinaldo, 1997; Rinaldo et al., 2006) pursuing an accurate de- scription of riverine hydraulic processes through the use of the geomorphologic dispersion (Rinaldo et al., 1991), providing a general framework to formulate spatially explicit models (e.g. Nicótina et al., 2008; Tobin et al., 2013). In such an approach, nonlinearities and nonstationarities of the hydrologic response (e.g. McDonnell et al., 2010; Botter et al., 2011; Sivapalan et al., 2002; Hrachowitz et al., 2013) are embedded in the parameterization of the soil moisture dynamics and the related dominant runoff generation processes at the source area scale.

The general model concept is introduced in Sect. 2 and implementation details discussed in Sect. 3. For illustration purposes, the model is applied to an example case study from Switzerland (Sect. 4), for which we discuss the discharge simulation performance in Sect. 5, before summarizing the main conclusions (Sect. 6).

\section{Model description}

The SEHR-ECHO model is composed of two main components (Fig. 1): (i) a precipitation-runoff transformation module that computes surface and subsurface water fluxes from the source areas (the basic sub-units that describe the spatial structure of the model domain), and (ii) a routing module that computes fluxes in the river network through to the control section (i.e. the outlet). In other terms, the model is composed of a module for unchannelled state processes at the source area scale and one for channelled state transport (Rinaldo et al., 2006).

The source areas are extracted from a digital elevation model (DEM) with the well-known Taudem algorithm (Tarboton, 1997) for subcatchment and river network delineation (see Sect. 4 for further details). The scale of these source areas are selected such as to allow for sufficiently homogeneous hydro-meteorological conditions without losing too much geomorphologic complexity. Relevant geomorphologic issues are discussed in Rodriguez-Iturbe and Rinaldo (1997).

\subsection{Precipitation-runoff module at source area scale}

The precipitation-runoff module solves the mass balance equations at the source area scale. This component is driven by precipitation, temperature and potential evaporation input time series, which need to be properly provided at the source area scale. The choice of methods to interpolate the observed input time series to this scale depends on the variable (precipitation, temperature), on the application and on the simulation time step (e.g. Tobin et al., 2011), and the choice of the general method is largely independent of the exact set-up of the hydrological model. In the remainder of this section we describe the precipitation-runoff transformation for one source area assuming the input variables are provided at the proper spatial and temporal scales. 


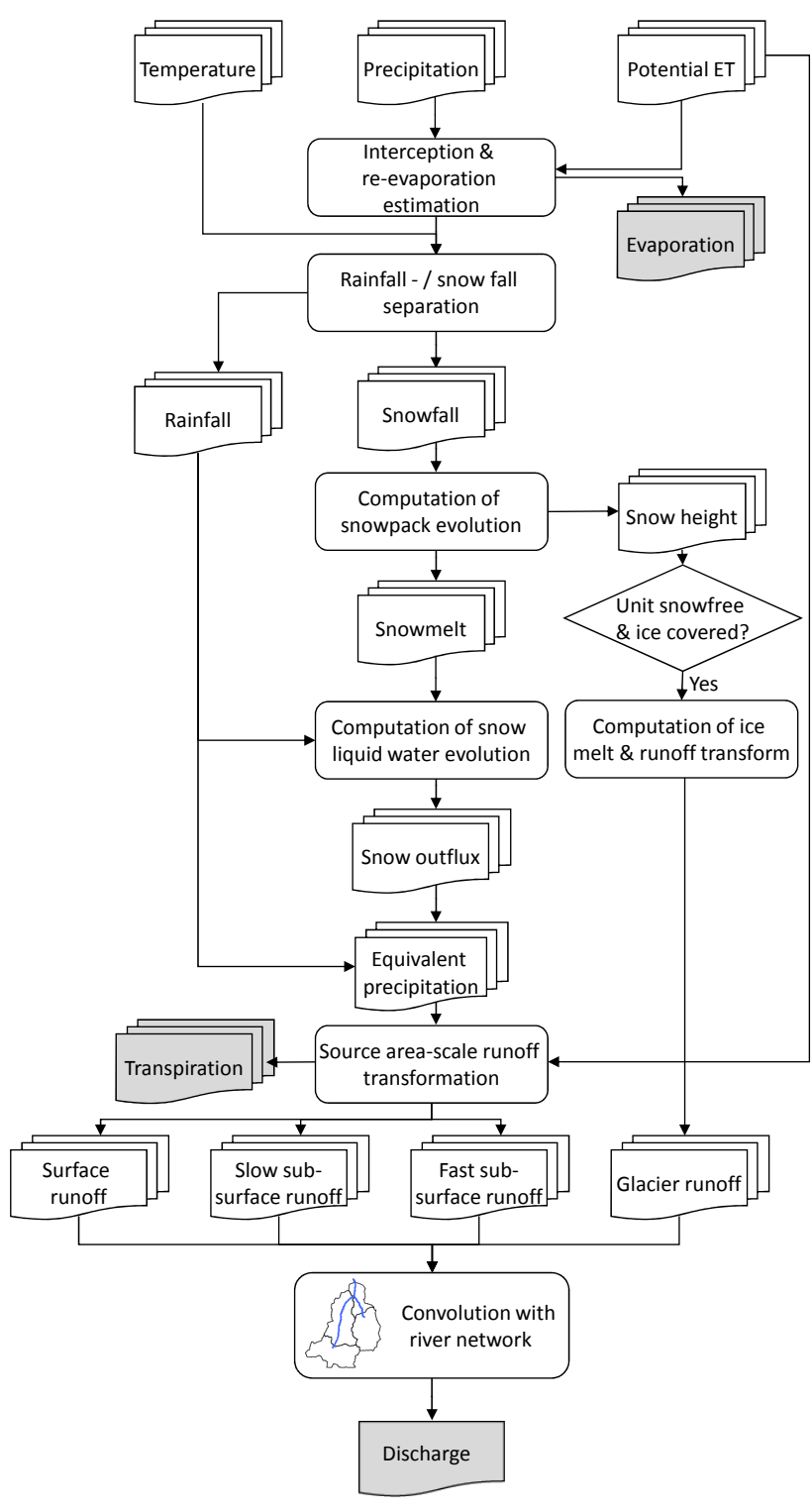

Figure 1. Flow diagram of the precipitation-discharge computation. The grey boxes highlight the model output time series.

The precipitation-runoff transformation module has the following key elements: interception and re-evaporation of intercepted water, rainfall/snowfall separation, evolution of water stored in the snowpack in solid form, evolution of the liquid water content of the snowpack and equivalent precipitation (rain and meltwater)-runoff transformation. If a source area has partial glacier cover, the runoff resulting from the glacier is computed separately (Fig. 1).

Interception $I_{\mathrm{c}}(t)$ is simulated using a constant interception capacity $\rho$ :

$I_{\mathrm{c}}(t)=\min [\rho, P(t)]$,

where $P(t)\left[\mathrm{LT}^{-1}\right]$ is the precipitation and $\rho\left[\mathrm{LT}^{-1}\right]$ is the maximum interception during a time step $t$ (e.g. Feni- cia et al., 2006). No separation between the aggregation state of precipitation (snow, rain) is made for $\rho$, a simplification which is not advisable for applications to catchments with considerable forest cover (e.g. Gelfan et al., 2004).

Part of the intercepted water is assumed to re-evaporate during the same time step, limited by potential evaporation $E_{\mathrm{pot}}(t)\left[\mathrm{LT}^{-1}\right]$ :

$E_{\mathrm{i}}(t)=\min \left[E_{\mathrm{pot}}(t), I_{\mathrm{c}}(t)\right]$,

where $E_{\mathrm{i}}(t)\left[\mathrm{LT}^{-1}\right]$ is the evaporation flux from intercepted water. This evaporated water is assumed to not be available for the precipitation-runoff generation process, i.e. total incoming precipitation is reduced to net precipitation $P_{\mathrm{n}}$ $\left[\mathrm{LT}^{-1}\right]$ :

$P_{\mathrm{n}}(t)=P(t)-E_{\mathrm{i}}(t)$.

$E_{\text {pot }}$ is reduced to potential transpiration $E_{\mathrm{t}, \mathrm{pot}}\left[\mathrm{LT}^{-1}\right]$ by the amount of $E_{\mathrm{i}}$ :

$E_{\mathrm{t}, \mathrm{pot}}(t)=E_{\mathrm{pot}}(t)-E_{\mathrm{i}}(t)$.

It is noteworthy that the above formulation assumes that interception is an instantaneous process, which takes place at timescales smaller than the simulation time step (i.e. subhourly). Only the evaporated water is subtracted from the incoming precipitation, which corresponds to a return of nonevaporated water as throughfall.

The estimation of the aggregation state of precipitation is based on a simple temperature threshold $T_{\mathrm{r}}\left[{ }^{\circ} \mathrm{C}\right]$ (Schaefli et al., 2005) that splits net precipitation $P_{\mathrm{n}}$ into rainfall $P_{\mathrm{r}}(t)\left[\mathrm{L} \mathrm{T}^{-1}\right]$ and snowfall $P_{\mathrm{s}}(t)\left[\mathrm{LT}^{-1}\right]$ depending on the mean temperature $T(t)$ (for a smooth threshold approach see Schaefli and Huss, 2011).

The evolution of the water equivalent of the snowpack height $h_{\mathrm{s}}[\mathrm{L}]$ is computed as

$\frac{\mathrm{d} h_{\mathrm{s}}}{\mathrm{d} t}=P_{\mathrm{s}}(t)-M_{\mathrm{s}}(t)+F_{\mathrm{S}}(t)-G_{\mathrm{s}}(t), h_{\mathrm{s}}>0$,

where $M_{\mathrm{S}}(t)\left[\mathrm{LT}^{-1}\right]$ is the snowmelt due to energy input from the atmosphere, $F_{\mathrm{S}}(t)\left[\mathrm{LT}^{-1}\right]$ is the flux of refreezing water during periods of negative heat input and $G_{\mathrm{s}}(t)\left[\mathrm{L} \mathrm{T}^{-1}\right]$ is the snowmelt due to ground-heat flux (all in water equivalent). $G_{\mathrm{s}}$ is assumed to be constant in time, $G_{\mathrm{s}}=G_{\max }$ as long as there is a snowpack:

$G_{\mathrm{s}}(t)= \begin{cases}G_{\max } & \text { if } h_{\mathrm{s}}(t)>0 \\ 0 & \text { if } h_{\mathrm{s}}(t)=0 .\end{cases}$

The snowmelt $M_{\mathrm{S}}$ is modelled as linearly related to positive air temperature according to the temperature-index or degree-day approach (Hock, 2003):

$M_{\mathrm{s}}(t)= \begin{cases}a_{\mathrm{S}}\left(T(t)-T_{\mathrm{m}}\right) & \text { if } T(t)>T_{\mathrm{m}}, h_{\mathrm{s}}(t)>0 \\ 0 & \text { otherwise }\end{cases}$ 
where $a_{\mathrm{s}}$ is the degree-day factor for snowmelt $\left[\mathrm{LT}^{-1}{ }^{\circ} \mathrm{C}^{-1}\right.$ ] and $T_{\mathrm{m}}\left[{ }^{\circ} \mathrm{C}\right]$ is the threshold temperature for melting that is set to $0^{\circ} \mathrm{C}$.

Refreezing $F_{\mathrm{S}}$ is assumed to occur when $T(t)<T_{\mathrm{m}}$ and is linearly related to negative air temperature with a freezing degree-day factor that is proportional to, but smaller than, the melt degree-day factor $a_{\mathrm{s}}$ (Kokkonen et al., 2006; Formetta et al., 2014):

$F_{\mathrm{S}}(t)= \begin{cases}a_{\mathrm{f}} a_{\mathrm{S}}\left(T_{\mathrm{m}}-T(t)\right) & \text { if } T(t)<T_{\mathrm{m}}, h_{\mathrm{s}}(t)>0 \\ 0 & \text { otherwise }\end{cases}$

where $a_{\mathrm{f}} \epsilon[0,1]$ is the degree-day reduction factor for refreezing.

The snowpack is assumed to have a certain water retention capacity $\theta \cdot h_{\mathrm{s}}[\mathrm{mm}]$ and water is released from the snowpack only if this retention capacity is exceeded. The balance equation for the liquid water $h_{\mathrm{w}}[\mathrm{L}]$ content of the snowpack is written as

$\frac{\mathrm{d} h_{\mathrm{w}}}{\mathrm{d} t}=P_{\mathrm{r}}(t)+M_{\mathrm{S}}(t)-F_{\mathrm{s}}(t)-M_{\mathrm{w}}(t)$

where the snowpack outflow $M_{\mathrm{w}}$ only occurs if the air temperature is above melting conditions and if the water retention capacity $\theta$ is reached:

$M_{\mathrm{W}}(t)= \begin{cases}P_{\mathrm{r}}(t)+M_{\mathrm{S}}(t)-F_{\mathrm{S}}(t) & \text { if } h_{\mathrm{W}}=\theta h_{\mathrm{S}} \\ 0 & \text { if } h_{\mathrm{w}}<\theta h_{\mathrm{s}}\end{cases}$

It is noteworthy that rainfall $P_{\mathrm{r}}$ only occurs if $T>T_{\mathrm{r}}$, snowmelt $M_{\mathrm{s}}$ only if $T>T_{\mathrm{m}}$ and refreezing $F_{\mathrm{s}}$ only if $T<T_{\mathrm{m}}$. It generally holds that $T_{\mathrm{r}}>T_{\mathrm{m}}=0{ }^{\circ} \mathrm{C}$, translating the well-known fact that snowfall can occur at temperatures above the melt temperature (for an analysis of observed snowfall at the Davos station, see Rohrer et al., 1994). The general case of Eq. (10) holds for all values of the threshold parameters or for fuzzy transitions between rain- and snowfall.

The water fluxes $P_{\mathrm{r}}, G_{\mathrm{S}}$ and $M_{\mathrm{w}}$ are summed up to produce the equivalent precipitation $P_{\mathrm{eq}}$ that enters the equivalentprecipitation-runoff transformation:

$P_{\mathrm{eq}}(t)= \begin{cases}P_{\mathrm{r}}(t) & \text { if } h_{\mathrm{s}}=0 \\ G_{\mathrm{S}}(t)+M_{\mathrm{W}}(t) & \text { if } h_{\mathrm{s}}>0\end{cases}$

The partitioning of equivalent precipitation into surface runoff, fast and slow subsurface runoff and transpiration resulting from water infiltration and percolation in the subsoil is performed via a minimalist description of the soil moisture dynamics at the source area scale (Laio et al., 2001; Rodriguez-Iturbe and Porporato, 2004; RodriguezIturbe et al., 1999):

$\eta Z_{\mathrm{r}} \frac{\mathrm{d} s(t)}{\mathrm{d} t}=F_{\mathrm{i}}(t)-E_{\mathrm{t}}(t)-L(t), \quad 0 \leq s \leq 1$, where $\eta[-]$ is the soil porosity, $Z_{\mathrm{r}}[\mathrm{L}]$ is the depth of the soil layer that is active during water redistribution processes, $s$ $[-]$ is the relative soil moisture in the active layer, $F_{\mathrm{i}}\left[\mathrm{L} \mathrm{T}^{-1}\right]$ is the infiltration rate, $E_{\mathrm{t}}\left[\mathrm{L} \mathrm{T}^{-1}\right]$ is the rate of transpiration of water from the root zone and $L\left[\mathrm{LT}^{-1}\right]$ is the water flux (called leakage here) mobilized from the root zone as subsurface flow.

It is noteworthy that this soil moisture dynamics equation, if forced with Poisson infiltration, can be solved exactly for a number of cases and forms the basis of substantial analytic work on the probabilistic properties of stream flow (Botter et al., 2007a, b; Botter, 2010).

The leakage $L$ is parameterized as a nonlinear function of the soil moisture as

$L(t)=K_{\mathrm{sat}} s(t)^{c}$,

where $K_{\text {sat }}\left[\mathrm{L} \mathrm{T}^{-1}\right]$ is the saturated hydraulic conductivity and $c$ the Clapp-Hornberger exponent (Clapp and Hornberger, 1978).

The transpiration rate is a linear function of relative soil moisture between the wilting point, $s_{\mathrm{W}}[-]$ (i.e. the moisture content below which the plants cannot further extract water from the soil) and the upper limit of water stress, $s_{\mathrm{m}}[-]$, at which it is assumed to reach the limit imposed by the potential transpiration rate (e.g Porporato et al., 2004):

$E_{\mathrm{t}}(t)=\min \left[E_{\mathrm{t}, \text { pot }} \frac{s-s_{\mathrm{W}}}{s_{\mathrm{m}}-s_{\mathrm{W}}}, E_{\mathrm{t}, \text { pot }}\right]$.

The infiltrated water corresponds to the equivalent precipitation from which direct surface runoff is subtracted:

$F_{\mathrm{i}}(t)=P_{\mathrm{eq}}(t)-R_{\mathrm{hort}}(t)-R_{\mathrm{dun}}(t)$,

where $R_{\text {hort }}\left[\mathrm{L} \mathrm{T}^{-1}\right.$ ] is surface runoff occurring if the infiltration capacity is exceeded and $R_{\text {dun }}\left[\mathrm{LT}^{-1}\right]$ is surface runoff occurring if the source area is saturated. These two mechanisms of surface runoff, inspired from Hortonian and Dunne overland flow (e.g. Dingman, 2002), enable the model to simulate different timescales of reaction to a precipitation or melt water input.

$R_{\text {hort }}$ is parameterized with a constant maximum infiltration capacity $\phi\left[\mathrm{L} \mathrm{T}^{-1}\right]$ :

$R_{\mathrm{hort}}(t)= \begin{cases}\max \left[P_{\mathrm{eq}}(t)-\phi, 0\right] & \text { if } s(t)<1 \\ 0 & \text { if } s(t)=1\end{cases}$

where $\phi$ is supposed to be constant in time. If the soil is saturated, $s(t)=1, R_{\text {dun }}$ occurs:

$R_{\text {dun }}(t)= \begin{cases}P_{\mathrm{eq}}(t) & \text { if } s(t)=1 \\ 0 & \text { if } s(t)<1\end{cases}$

The water mobilized from the active layer $L$ is transformed to subsurface runoff at the source area outlet through two 
linear reservoirs that simulate a fast and a slow subsurface flux, $R_{\text {fast }}\left[\mathrm{LT}^{-1}\right]$ and $R_{\text {slow }}\left[\mathrm{LT}^{-1}\right]$ (similar to e.g. the formulation in the HBV model Bergström, 1995). The part of $L$ feeding the slow subsurface flux, $L_{\text {slow }}$, is assumed to be a constant flux $L_{\max }$ limited by $L$ :

$L_{\text {slow }}(t)=\min \left[L(t), L_{\max }\right]$.

The linear reservoir equations for the fast and slow subsurface runoff thus read as

$\frac{\mathrm{d} S_{\text {fast }}}{\mathrm{d} t}=L(t)-L_{\text {slow }}(t)-R_{\text {fast }}(t)$,
$\frac{\mathrm{d} S_{\text {slow }}}{\mathrm{d} t}=L_{\text {slow }}(t)-R_{\text {slow }}(t)$,

where $S_{\text {fast }}$ [L] and $S_{\text {slow }}$ [L] are the water storage in the fast and the slow reservoirs. $R_{\text {fast }}\left[\mathrm{LT}^{-1}\right]$ and $R_{\text {slow }}\left[\mathrm{L} \mathrm{T}^{-1}\right]$ are the fast and slow reservoir outflows, which are supposed to linearly depend on the storage, i.e. $R_{\text {fast }}=k_{\text {fast }} S_{\text {fast }}$ and $R_{\text {slow }}=k_{\text {slow }} S_{\text {slow }}$, where $k_{\text {fast }}^{-1}[\mathrm{~T}]$ and $k_{\text {slow }}^{-1}[\mathrm{~T}]$ are the mean residence times.

Note that $s$ is a relative soil moisture, whereas $S_{\text {slow }}$ and $S_{\text {fast }}$ have length units.

\subsection{Discharge simulation from glacierized subcatchments}

If a source area has a partial glacier coverage, ice is assumed to start melting if $h_{\mathrm{s}}=0$ (Schaefli et al., 2005):

$M_{\mathrm{i}}= \begin{cases}a_{\mathrm{i}}\left(T(t)-T_{\mathrm{m}}\right) & \text { if } T(t)>T_{\mathrm{m}}, h_{\mathrm{s}}(t)=0 \\ 0 & \text { otherwise, }\end{cases}$

where $a_{\mathrm{i}}\left[\mathrm{L} \mathrm{T}^{-1}{ }^{\circ} \mathrm{C}^{-1}\right]$ is the degree-day factor for ice melt. This melt is routed to the subcatchment outlet through a linear reservoir with coefficient $k_{\text {ice }}$. The routing to the catchment outlet follows the general procedure (see hereafter) but the flux is weighted according to the fraction of source area that is glacier covered. No glacier surface dynamics are modelled (e.g Huss et al., 2010) and the glacier cover is assumed to be constant (but it can of course be updated for different simulation periods).

\subsection{Discharge simulation at catchment outlet}

The transport of the runoff components through the river network uses a linear approach, assuming that most relevant nonlinear processes are captured through the source areascale precipitation-runoff transformation. This assumption only holds for systems where flow velocity can be assumed to be relatively constant in time (independent of discharge) and space. The total discharge at the catchment outlet is obtained by convolution of each of the fluxes $R$ (surface runoffs $R_{\text {hort }}$, $R_{\text {dun }}$, subsurface runoffs $R_{\text {fast }}, R_{\text {slow }}$ and ice melt runoff $R_{\text {ice }}$ ) from all source areas with a travel time distribution $f_{\gamma}(t)$ along its flow path $\gamma$ to the catchment outlet (Fig. 2).

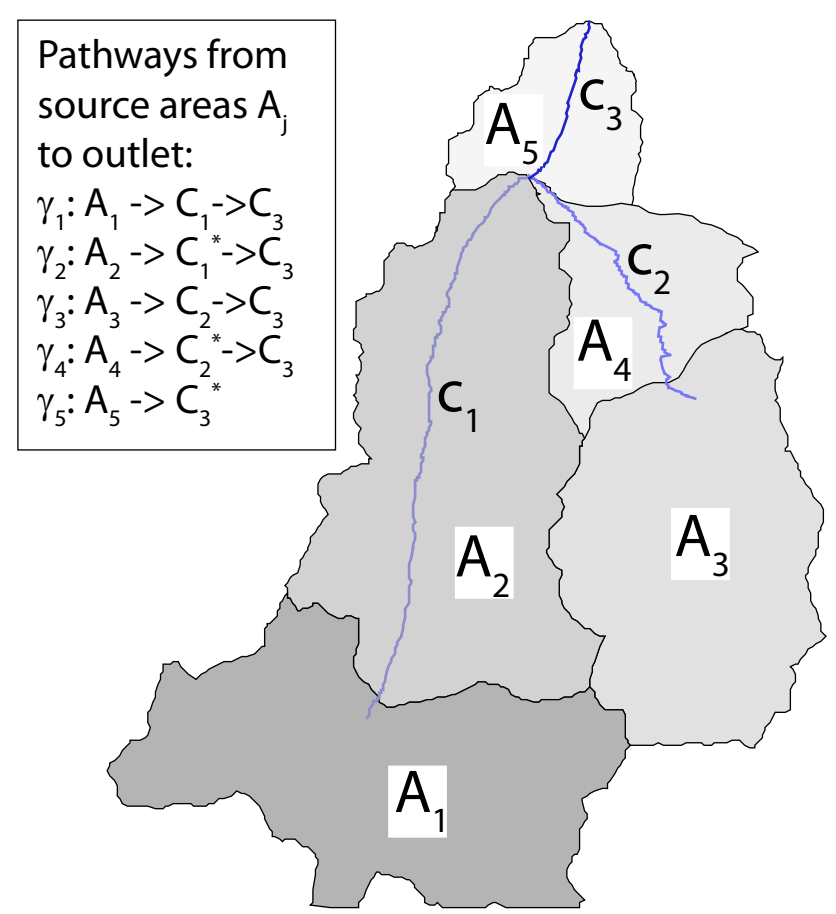

Figure 2. Sketch of the flow paths from a catchment with five source areas $A_{j}$ and three channels $C_{j}$. The notation $C_{j}^{*}$ means that the injection into this channel is not concentrated at the upstream end but, in theory, randomized and integrated over the channel length (Bras and Rodriguez-Iturbe, 1985). In practice, we take half of the channel length.

The probability density functions of travel times, $f_{\gamma}(t)$ (assumed statistically independent) are obtained from the travel time distributions in all channels $C_{j} \rightarrow C_{k} \rightarrow C_{\Omega}$ composing them (Gupta et al., 1980; Rinaldo et al., 1991):

$f_{\gamma}(t)=f_{C_{j}}(t) * f_{C_{k}}(t) * \cdots * f_{\Omega}(t)$,

where $*$ is the convolution operator and $\Omega$ is the outlet. For the example illustrated in Fig. 2, the travel path from the source area $A_{1}$ to the outlet is made up of two collecting channels $C_{1}$ and $C_{3}$.

The travel time distributions within channelled states $C_{j}$ are obtained assuming longitudinal 1-D dispersion, which is a reasonable assumption for open channel flow in low-order rivers (Rinaldo et al., 1991):

$f_{C_{j}}(t)=\frac{1}{4\left(\pi D_{\ell} t^{3}\right)^{(1 / 2)}} \ell_{j} \exp \left\{-\left[\frac{\left(\ell_{j}-v t\right)^{2}}{4 D_{\ell} t}\right]\right\}$,

where $D_{\ell}\left[\mathrm{L}^{2} \mathrm{~T}^{-1}\right]$ is the hydrodynamic dispersion coefficient, $\ell_{j}[\mathrm{~L}]$ is the channel length and $v\left[\mathrm{LT}^{-1}\right]$ is the average velocity.

The simulated discharge at the catchment outlet becomes

$Q=Q_{\text {fast }}+Q_{\text {slow }}+Q_{\text {hort }}+Q_{\text {dun }}+Q_{\text {ice }}$, 
Table 1. Model parameters describing the physiographic catchment characteristics. The units are given in generic terms (L: length).

\begin{tabular}{lll}
\hline Symbol & Unit & Meaning \\
\hline$A_{\gamma}$ & $\mathrm{L}^{2}$ & Source area size \\
$n$ & - & Number of source areas \\
$\ell_{\gamma}$ & $\mathrm{L}$ & Path length \\
$H_{\gamma}$ & La.s.l. & Mean source area elevation \\
\hline
\end{tabular}

where each of the discharge components $Q_{x y z}$ equals

$$
Q_{x y z}=\sum_{\gamma=1}^{n}\left[R_{x y z, \gamma}(t) \cdot f_{\gamma}(t)\right] \text {. }
$$

\section{Model implementation}

The model requires temperature, precipitation and potential evaporation time series for each subcatchment and, for model calibration, at least one concomitant discharge time series observed at the catchment outlet. The numerical implementation uses a fixed time step and a fourth-order Runge-Kutta scheme to compute the soil moisture evolution. The other stores (fast and slow subsurface flux stores, solid and liquid snow stores) are solved with explicit time stepping, which is justified given that these stores have only one outflux, linearly dependent on the storage.

The provided code (see Sect. "Code availability") is developed in Matlab R2010b. The parameterization of each of the presented hydrological processes can easily be modified. The basic model structure (passing of variables and parameters among functions) has been designed for an easy combination with the now widely used optimization algorithms developed by Vrugt et al. (2003, 2009). For the example presented in this paper, the model is, however, calibrated with simple Monte Carlo generation within a priori parameter ranges (details in Sect. 4).

\subsection{Identification of model parameter patterns}

The physical parameters of SEHR-ECHO, which describe the physiographic catchment characteristics and can be extracted from topographic data, are listed in Table 1. The model parameters that require calibration or a relevant method of a priori estimation are summarized in Table 2 (along with a range of a priori values). Depending on the application, all these parameters might be made variable in space, especially the ones for which there are known spatial patterns.

It is, in particular, recommended to relate the mean residence time $k_{\text {fast }}^{-1}$ of subcatchment-scale subsurface fluxes to the source area $A_{\gamma}$, as

$$
\frac{1}{k_{\text {fast }, \gamma}} \sim A_{\gamma}^{\xi},
$$

where the scaling coefficient $\xi$ can be set to values of around 1/3 (Alexander, 1972; Pilgrim et al., 1982). In practical terms, such a scaling for $k_{\text {fast }}$ is obtained by calibrating a generic reservoir coefficient $k_{\mathrm{cal}}$ such that

$\frac{1}{k_{\text {fast }, \gamma}}=\frac{1}{k_{\text {cal }}}\left(\frac{A_{\gamma}}{\left\langle A_{\gamma}\right\rangle}\right)^{\xi}$,

where $\left\langle A_{\gamma}\right\rangle$ is the mean subcatchment area. The coefficient $k_{\text {slow }}$ is then related to $k_{\text {fast }}$ through the calibration of a multiplication parameter $m_{k}$ such that

$$
\frac{1}{k_{\text {slow }, \gamma}}=m_{k} \frac{1}{k_{\text {fast }, \gamma}} \text {. }
$$

It might be tempting to derive the spatial variability of the active soil depth from soil production theory (Heimsath et al., 1997). Such an approach might e.g. assume that the soil depth of a source area is proportional to the mean topographic curvature in topographically convex areas. Another idea could be to identify topographically concave areas that can be assumed to be saturated at all times. For applications similar to the one presented here, different model tests showed, however, that the effect of spatially variable soil depth on simulated discharge can be compensated by the other model parameters (Nicótina et al., 2011); this approach is therefore not further pursued here.

The saturated hydraulic conductivity can easily be distributed in space according to observed land use and soil types; an example is discussed in Sect. 4 for the present case study. Imposing additional spatial parameter patterns related to directly observable physiographic characteristics is readily possible, but beyond the scope of the present work.

\section{Case study}

The Dischmabach catchment, located in the southeast of Switzerland near Davos (Fig. 3), has a size of $43.3 \mathrm{~km}^{2}$ at the Kriegsmatten gauging station, for which long discharge time series are available from the Swiss Federal Office for the Environment. Its elevation ranges from 1668 up to $3146 \mathrm{~m}$ a.s.l. (mean altitude $2372 \mathrm{ma.s.1}$.) with around $2.1 \%$ of the catchment area covered by glaciers. The annual mean temperature at mean elevation is around $-0.5^{\circ} \mathrm{C}$. The discharge regime shows a strong seasonal pattern due to accumulation and melting of snow. The relatively steep hillslopes are covered with pasture $(38 \%)$ and forest $(10 \%)$; around $16 \%$ of the catchment are bare soil, rock outcrops cover $24 \%$ (Verbunt et al., 2003). The geology is crystalline composed of gneiss and amphibolites, overlain by shallow soils (Verbunt et al., 2003). The nearby meteorological station of Weissfluhjoch (2690 ma.s.1.) records around $1450 \mathrm{mmyear}^{-1}$ of precipitation (period 1981-1999), which is relatively low compared to other Alpine locations at the same altitude. The discharge over the same period was around 1350 mm year $^{-1}$. The mean 
Table 2. Model parameters that have to be calibrated or estimated otherwise with indication of a priori values, a reference value for parameters that are not calibrated here and key references for further details. A total of 12 parameters are calibrated here. The maximum value of the reservoir coefficient is the numerical time step.

\begin{tabular}{llrrrll}
\hline Symbol & Unit & Min. & Max. & Ref. value & Meaning & Source \\
\hline$\rho$ & $\mathrm{mm}$ & 0 & 3 & - & Interception threshold & Gerrits et al. (2010) \\
$T_{\mathrm{r}}$ & ${ }^{\circ} \mathrm{C}$ & 0 & 6 & 1 & Rain temperature threshold & Tobin et al. (2012) \\
$a_{\mathrm{S}}$ & $\mathrm{mm}^{\circ} \mathrm{C}^{-1} \mathrm{~d}^{-1}$ & 1 & 6 & - & Degree-day fact. snow & Schaefli et al. (2005) \\
$a_{\mathrm{i}}$ & $\mathrm{mm}^{\circ} \mathrm{C}^{-1} \mathrm{~d}^{-1}$ & 4 & 12 & - & Degree-day fact. ice & Schaefli et al. (2005) \\
$a_{\mathrm{f}}$ & - & 0 & 1 & 0.2 & Degree-day freezing fact. & Kokkonen et al. (2006) \\
$\theta$ & - & 0 & 0.1 & 0.05 & Snow retention capacity & Dingman (2002) \\
$G_{\mathrm{max}}$ & $\mathrm{mm} \mathrm{d}^{-1}$ & 0 & 2 & - & Max. ground-heat melt & Pomeroy et al. (1998); Dingman (2002) \\
$\eta$ & - & 0.3 & 0.55 & 0.4 & Soil porosity & Dingman (2002) \\
$Z_{\mathrm{r}}$ & $\mathrm{mm}$ & 50 & 1500 & - & Root zone depth & \\
$L_{\mathrm{max}}$ & $\mathrm{mmh}^{-1}$ & 0 & 0.15 & - & Max. deep leakage & see Sect. 3 \\
$c$ & - & 3.3 & 30 & - & Clapp-Hornberger exponent & Clapp and Hornberger (1978) \\
$K_{\text {sat }}$ & $\mathrm{mmh}^{-1}$ & 0.01 & 500 & - & Saturated hydraul. conductivity & Dingman (2002) \\
$s_{\mathrm{W}}$ & - & 0.1 & 0.4 & - & Wilting point & Dingman (2002) \\
$s_{\mathrm{m}}$ & - & 0.4 & 0.6 & - & Plant stress point & Dingman (2002) \\
$k_{\text {slow }}$ & $\mathrm{h}^{-1}$ & $1 /(365 \cdot 24)$ & 1 & - & Slow subsurface flux coeff. & see Sect. 3 \\
$k_{\text {fast }}$ & $\mathrm{h}^{-1}$ & $1 /(10 \cdot 24)$ & 1 & - & Fast subsurface flux coeff. & see Sect. 3 \\
$k_{\text {ice }}$ & $\mathrm{h}^{-1}$ & $1 /(15 \cdot 24)$ & 1 & - & Ice melt reservoir coeff. & Schaefli et al. (2005) \\
$\phi$ & $\mathrm{mmh}^{-1}$ & 1 & $\infty$ & $\infty$ & Max. soil infiltration capacity. & see Sect. 4 \\
$v$ & $\mathrm{~m} \mathrm{~s}^{-1}$ & 0.1 & 2 & 0.5 & Water flow velocity & Comiti et al. (2007); Yochum et al. (2012) \\
\hline
\end{tabular}
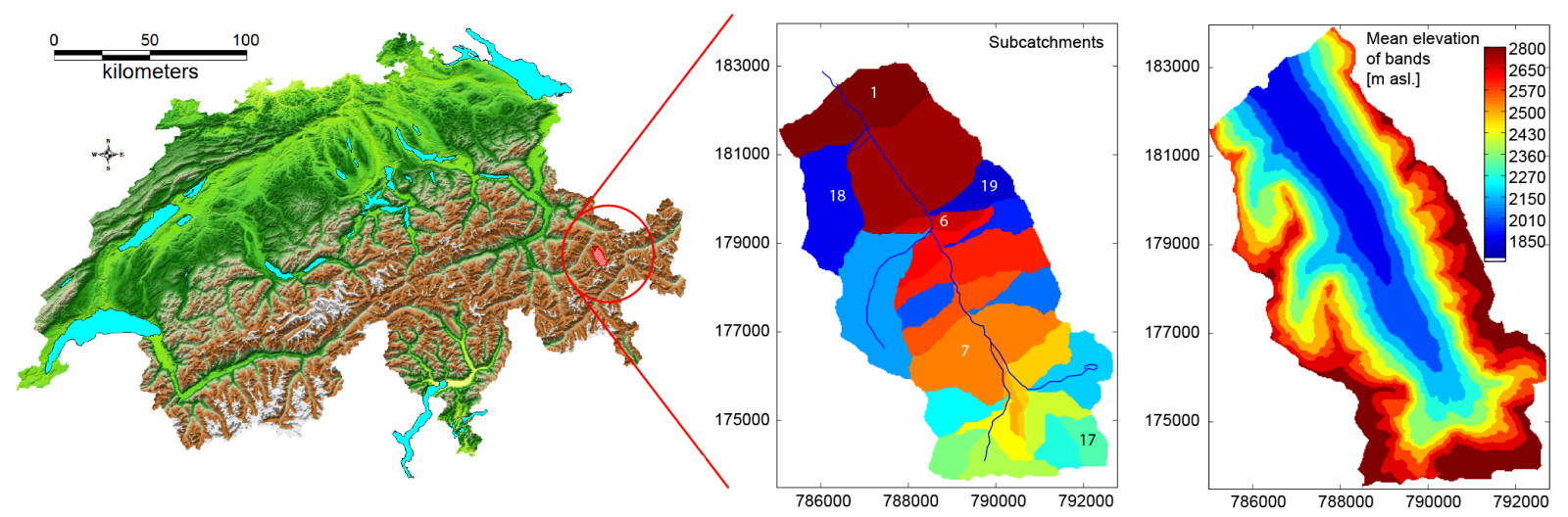

Figure 3. Location of the Dischmabach catchment within Switzerland (source: SwissTopo, 2005, 2008) and the 23 subcatchments identified with TauDEM Version 5 (Tarboton, 1997). The 10 elevation bands in the right plot are used for comparison purposes in Sect. 5.1. The latitude and longitude are indicated in the Swiss coordinate system (in $\mathrm{km}$ ).

evaporation in this catchment is around 300 mm year $^{-1}$ for the period 1973-1992 (Menzel et al., 1999). Part of the discharge is due to net glacier ice melt.

The subcatchments as well as the river network characteristics required to run the model (network topology, river reach lengths) are identified with TauDEM Version 5 (Tarboton, 1997), a hydrologic terrain analysis tool which is freely available under the terms of the GNU General Public License version 2 at http://hydrology.usu.edu/taudem/ taudem5/. The 23 subcatchments as well as the river network are shown (Fig. 3).

The temperature time series for each subcatchment is obtained through a linear interpolation of the temperature ob- served at the Davos weather station (1594 ma.s.l.) to the mean subcatchment altitude, using the average temperature lapse rate between this and the Weissfluhjoch station (which equals $-0.50{ }^{\circ} \mathrm{C} / 100 \mathrm{~m}$ ). The precipitation for each subcatchment is the one recorded at Weissfluhjoch. The potential evaporation is evaluated with the Priestley-Taylor method (Maidment, 1993; Priestley and Taylor, 1972) using the Weissfluhjoch meteorological data.

Given the important heterogeneity of land use in this catchment, we distribute the saturated hydraulic conductivity according to land use types, which are available from the Swiss land use database at a resolution of $100 \mathrm{~m}$ (Swiss Federal Office for Statistics, 2001). We assign each relevant land 
use class $j$ a surface runoff coefficient $r_{j}$ (see Supplement, Table S1). Based on the distribution of $r_{j}$ within each subcatchment $\gamma$, we compute the following scaling parameter:

$\varrho_{\gamma}=\frac{\sum_{j} r_{j} f_{j}}{r_{\mathrm{D}}}$

where $\gamma$ identifies a given subcatchment, $f_{j}$ is the relative frequency of occurrence of the land use class $j$ within the subcatchment and $r_{\mathrm{D}}$ is the surface runoff coefficient of the dominant land use class.

For each subcatchment, the saturated hydraulic conductivity is then obtained as

$K_{\text {sat }, \gamma}=\varrho_{\gamma} K_{\text {sat }}$,

where $K_{\text {sat }}$ is obtained through calibration.

Impervious subcatchment areas are accounted for by setting the soil depth of the corresponding portions to 0 (in total $1.2 \mathrm{~km}^{2}$ ).

\subsection{Model calibration}

For the purpose of this paper, the model is calibrated on daily and hourly discharge with simple Monte Carlo simulation: we draw a high number of random parameter sets in the a priori parameter ranges and retain the best simulations with respect to the well-known Nash-Sutcliffe performance criterion (Nash and Sutcliffe, 1970), which evaluates how much better the simulated discharge $Q_{\mathrm{s}}$ fits the observed discharge $Q_{\text {o }}$ than the simplest possible model, the mean of the observed discharge over the entire period $\overline{Q_{0}}$ :

$N\left(Q_{\mathrm{s}}\right)=1-\frac{\sum_{i=1}^{n_{t}}\left(Q_{\mathrm{o}}\left(t_{i}\right)-Q_{\mathrm{s}}\left(t_{i}\right)\right)^{2}}{\sum_{i=1}^{n_{t}}\left(Q_{\mathrm{o}}\left(t_{i}\right)-\overline{Q_{\mathrm{o}}}\right)^{2}}$,

where $N$ is the Nash-Sutcliffe efficiency, NSE, and $t_{i}$ the $i$ th time step, $i=1, \ldots, n_{t}$. In addition, we analyse the NSE-log value computed on log-transformed discharges $\left(N_{\mathrm{L}}\right)$ and the relative bias between the simulated and the observed mean discharge.

For hydrological regimes with a strong annual discharge cycle, the above NSE value is not very meaningful since any model that reproduces the annual cycle more or less will have a high NSE value (Schaefli and Gupta, 2007). We therefore compute the benchmark NSE value, $N\left(Q_{\mathrm{b}}\right)$, for a benchmark model which corresponds to the average of all observed discharges on a given time step $k$ of the year $y$ (either a Julian day or an hour of a Julian day) (Schaefli and Gupta, 2007):

$Q_{\mathrm{b}}(k)=\sum_{y=1}^{Y} Q_{\mathrm{o}}\left(k_{y}\right)$

where $k_{y}$ is the $k$ th time step of year $y$ and $Y$ the total number of years. For the observed discharge of the Dischmabach, $N\left(Q_{\mathrm{b}}\right)$ equals 0.74 at the daily time step and 0.73 at the hourly time step. For $N_{\mathrm{L}}\left(Q_{\mathrm{b}}\right)$ the values of the benchmark is 0.87 for the daily and the hourly time step.

Given the insignificant role of Horton direct runoff in this environment, this runoff mechanism is deactivated here (assuming infinite infiltration capacity). For all other processes, the a priori parameter ranges are obtained based on existing literature (see Table 2). The upper limit of the percolation flux feeding the slow subsurface flux, $L_{\max }$, is chosen equal to the mean daily precipitation. The upper limit of the average root zone depth is fixed to $1.5 \mathrm{~m}$, which is a conservative estimate given the type of vegetation present. The generic fast subsurface residence time, $k_{\mathrm{cal}}$, Eq. (27), is assumed to be of the order of magnitude of days and the slow subsurface residence to be substantially longer (maximum scaling factor $\left.m_{k}=50\right)$.

A similar scaling approach is also used to ensure that the degree-day factor for ice $a_{\mathrm{i}}$ is higher than the one for snow $a_{\mathrm{s}}$ and that the retention capacity $s_{\mathrm{m}}$ is higher than the wilting point $s_{\mathrm{w}}$.

\section{Results}

For the Dischma catchment, a total of 12 model parameters have to be calibrated, seven for the water input-runoff transform and five for the glacier and snowmelt simulation. Here, these calibration parameters have been estimated through simple Monte Carlo simulation to illustrate the main features of the SEHR-ECHO model. Figure 4 shows the discharge simulation along with the simulated series of evapotranspiration and observed meteorological time series at the catchment outlet for the best NSE parameter set obtained with 35000 parameter sets sampled uniformly within the prior distributions of Table 2. With a NSE value of 0.82 during calibration, this parameter set performs better than the benchmark model (Sect. 4). It furthermore gives reasonable estimates for evapotranspiration, which indicates that the observed precipitation time series is an acceptable proxy for catchment-scale area-average precipitation input.

The splitting between the three hillslope scale runoff generation processes corresponds to the expected pattern: Fig. 5 illustrates that the slow subsurface component contributes essentially to base flow and that the direct surface runoff is activated only occasionally. It is noteworthy, however, that this pattern results partially from the imposed subsurface residence time scaling. (The corresponding subcatchment scale state variables are given in Fig. S1 of the Supplement along with an example of the simulated snowpack evolution, Fig. 2.)

This parameter set comes along with a number of sets that lead to equally good discharge simulations for the reference performance criteria for the calibration period. The plots of NSE vs. NSE-log and of NSE vs. the relative bias (Fig. 6) illustrate that these performance criteria can be well optimized simultaneously, which is not always the case for hydrologi- 

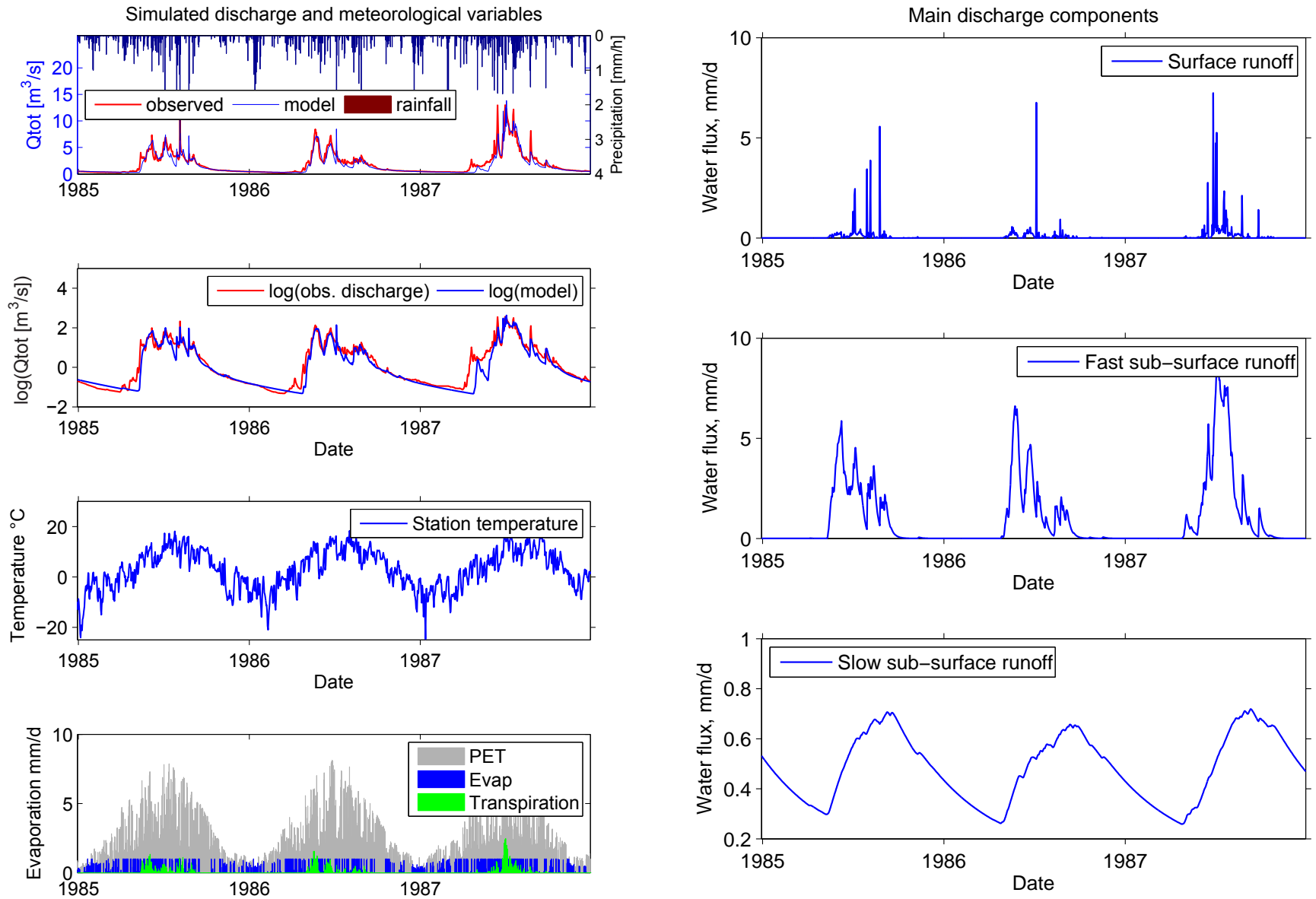

Figure 4. Observed and simulated hydro-meteorological time series of model state variables for the parameter set of Table 3 .

cal models. Such models typically show a strong tradeoff between NSE and NSE-log because the same set of processes cannot reproduce high flows and recessions. This problem is reduced in the analysed hydrologic regime where low flows are dominated by the long winter recession, relatively simple to simulate (see also the log discharge plot in Fig. 4).

A notable aspect of this SEHR-Echo application is that a large number of the best-performing parameter sets at the daily time step perform equally well during the calibration period (1981-1992) and the validation period (1993-2000) and at the hourly time step (Fig. 6). This is also illustrated in Fig. 7 which shows the ensemble of discharge simulations obtained for the 100 best daily parameter sets (see Fig. 8) applied at the daily and the hourly simulation time step. The corresponding prediction limits span the observed discharge equally well at both time steps. The simulation bias increases however at the hourly time step (Table 3): this is most likely due to the assumption of a constant within-day relation between air temperature and snowmelt and refreezing and ice melt; the related parameters might require a specific calibra-

Figure 5. Time series of the streamflow components (direct surface flow, fast subsurface flow and slow (deep) subsurface flow) corresponding to the parameter set of Table 3 and the discharge plot of Fig. 4.

tion to the hourly time step or a more appropriate formulation for the hourly time step (Tobin et al., 2013).

A comparable assessment of model performance at different timescales without re-calibration is rarely reported in the literature. For an example, see the work of Schaake et al. (1996).

The above evidence, timescale independence and splitting between the runoff generation processes, are important hints that the model works well for the right reasons: the parameters play the role they have been designed for, rather than trying to mimic omitted runoff generation processes or to compensate for the lack of spatial differentiation of travel times, which might typically occur for lumped models.

This conclusion is also supported by the good identifiability of some of the model key parameters, illustrated by the relatively peaky distributions in Fig. 8, which shows histograms of the best 100 parameter sets (in terms of NSE) at the daily time step. Albeit not providing a formal assessment of model and parameter uncertainty, this simple analysis illustrates that the model has a relatively well defined range of 
Table 3. The calibrated parameter values corresponding to the parameter set with the best NSE value at the daily time step for the calibration period. The performance criteria values of this set are: $\mathrm{NSE}($ day, calib $)=0.82, \mathrm{NSE}_{\log }($ day, calib $)=0.85$, bias $($ day, calib $)=-0.03, \mathrm{NSE}($ day, valid $)=0.76, \mathrm{NSE}_{\log }$ (day, valid $)=0.86$, bias $($ day, valid $)=0.05, \operatorname{NSE}($ hour, valid $)=0.78$, $\mathrm{NSE}_{\log }($ hour, valid $)=0.87$, bias $($ hour, valid $)=-0.12$.

\begin{tabular}{llr}
\hline Symbol & Unit & Value \\
\hline$a_{\mathrm{S}}$ & $\mathrm{mm}^{\circ} \mathrm{C}^{-1} \mathrm{~d}^{-1}$ & 2.14 \\
$a_{\mathrm{i}}$ & $\mathrm{mm}^{\circ} \mathrm{C}^{-1} \mathrm{~d}^{-1}$ & 6.22 \\
$G_{\mathrm{max}}$ & $\mathrm{mm} \mathrm{d}^{-1}$ & 0.18 \\
$Z_{\mathrm{r}}$ & $\mathrm{mm}$ & 184.75 \\
$L_{\text {max }}$ & $\mathrm{mm} \mathrm{h}^{-1}$ & 0.12 \\
$c$ & - & 5.87 \\
$K_{\text {sat }}$ & $\mathrm{mm} \mathrm{h}^{-1}$ & 231.96 \\
$s_{\mathrm{W}}$ & - & 0.27 \\
$s_{\mathrm{m}}$ & - & 0.77 \\
$k_{\text {slow }}^{-1}$ & $\mathrm{~d}$ & 146.87 \\
$k_{\text {fast }}^{-1}$ & $\mathrm{~d}$ & 6.50 \\
$k_{\text {ice }}^{-1}$ & $\mathrm{~d}$ & 22.30 \\
\hline
\end{tabular}
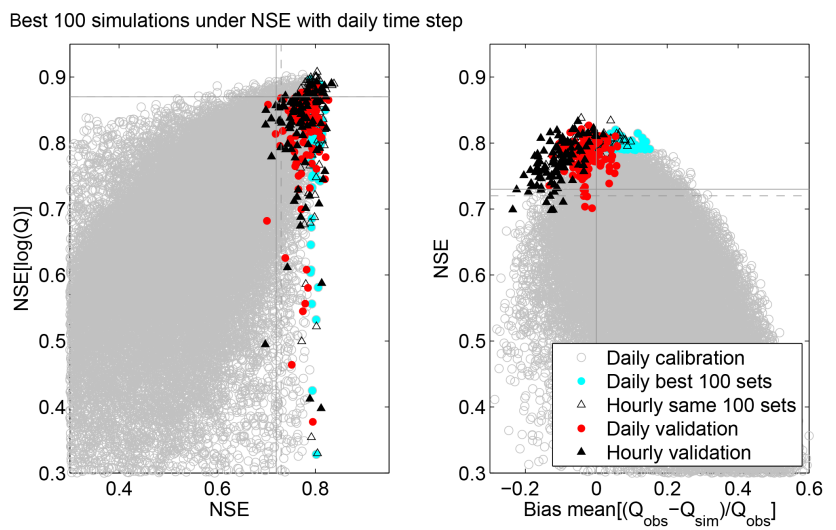

Figure 6. NSE vs. NSE-log for all simulated parameter sets during model calibration with daily time step (period 1981-1994), values for 100 parameter sets with best NSE values, values for the same parameter sets simulated over validation period (1993-2003) and values for the same parameter sets simulated at hourly time step over the validation period. The lines indicate the benchmark values for daily and hourly (broken line) time steps.

optimal parameters, which might be further refined for realworld applications and specific questions (e.g. extreme event analysis). It is noteworthy, however, that a flat distribution of the best-performing parameter sets for a given specific parameter (e.g. here the wilting point) does not point towards model insensitivity with respect to this parameter, since its relation to other parameters might simply not be visible in the marginal distribution (Bardossy, 2007).
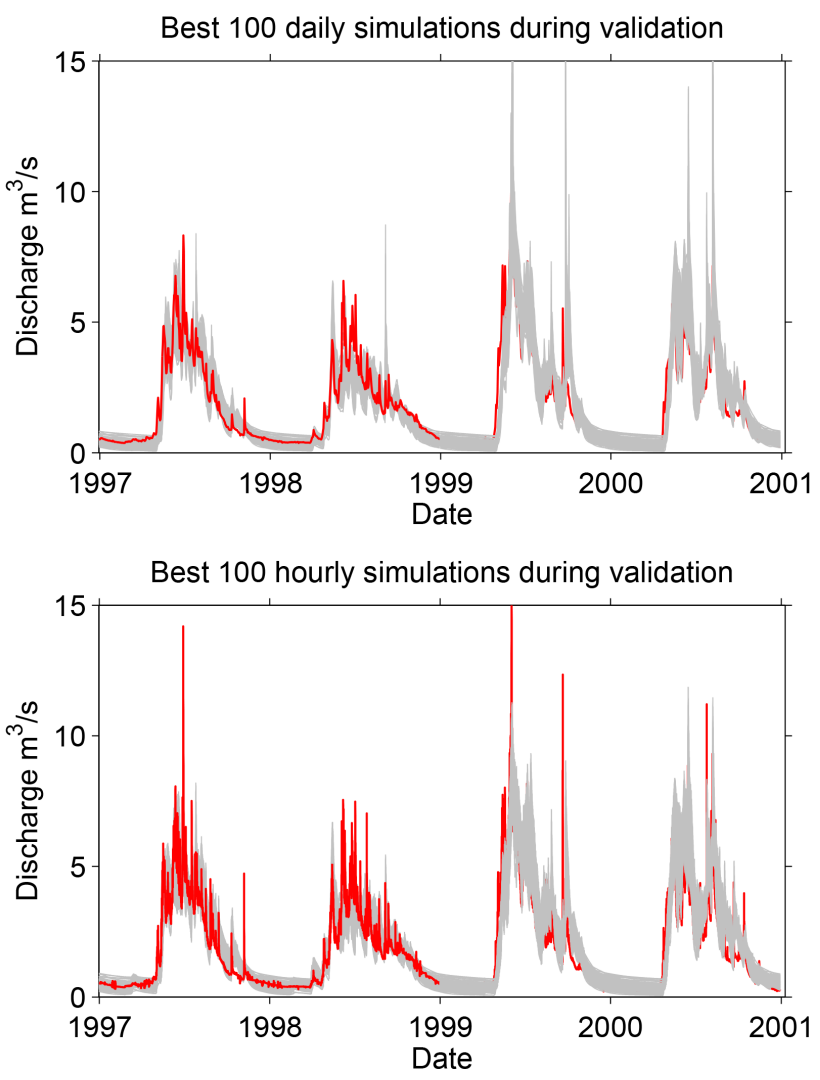

Figure 7. Predictions resulting from the 100 best parameter sets obtained under NSE for a daily time step (of the total 35000 Monte Carlo simulations); top: simulation at the daily time step, bottom: simulation at the hourly time step (same parameter sets). The first half of the plot shows that the prediction limits are reasonably narrow, the reserved plotting order in the second half shows that the observations are well spanned - 79\% (daily) respectively $75 \%$ (hourly) of the observed time steps fall into the range spanned by the simulations.

The question arises as to how far the geomorphologybased set-up and the routing scheme influence the results. The model simulations are insensitive to hydrodynamic dispersion since its effect is overruled by advection. Given the relatively short distances in this catchment (the longest travel paths from a subcatchment to the outlet is $11 \mathrm{~km}$ ), the velocity of in-stream discharge routing has only a minor effect at the daily timescale and a notable influence of the velocity on the simulated discharge would be obtained only with unrealistically low velocities (e.g. Yochum et al., 2012) (Fig. 9). For the hourly time step, any variation of flow velocity affects the discharge simulation and including this parameter in the calibration process might be a possible option, keeping in mind, however, that it might interact with the recession coefficients. 

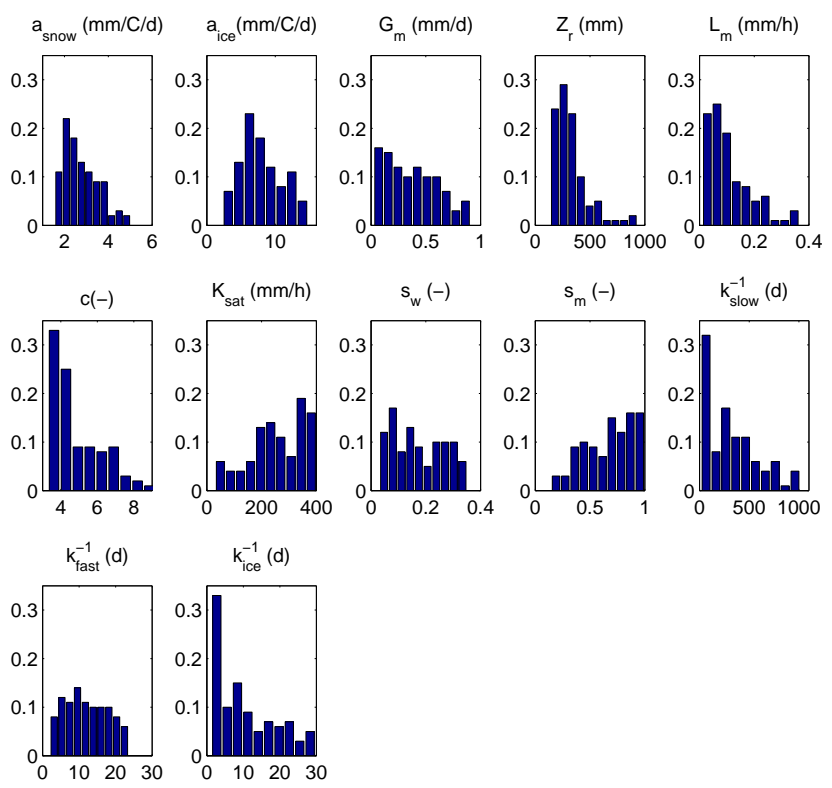

Figure 8. Parameter distributions obtained for the best 100 parameter sets under NSE at a daily time step. The $y$-axis shows the relative frequency of parameter values in each bin. $s_{\mathrm{m}}, k_{\text {slow }}$ respectively $a_{\mathrm{i}}$ result from a multiplication of $s_{\mathrm{W}}, k_{\mathrm{fast}}$ respectively $a_{\mathrm{S}}$ with the distribution of the corresponding calibrated scaling parameters.

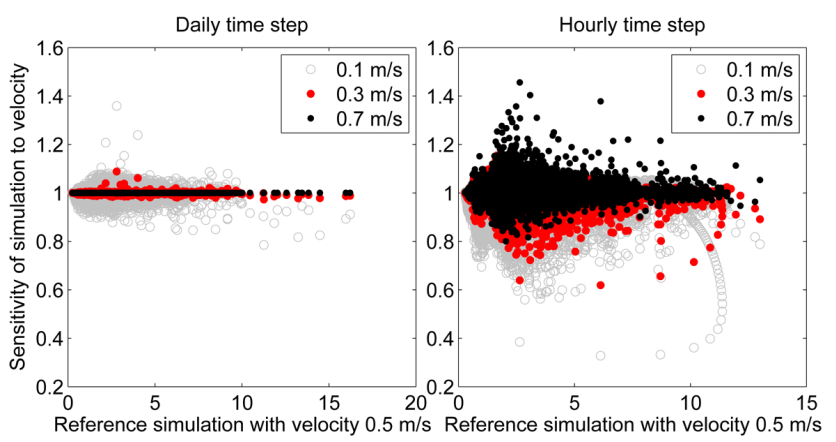

Figure 9. Sensitivity of the discharge simulation with respect to the in-stream flow velocity plotted against the reference simulation with parameters of Table 3 and velocity of $0.5 \mathrm{~m} \mathrm{~s}^{-1}$; the sensitivity is expressed as the relative difference to the reference simulation for each time step.

\subsection{Comparison of the subcatchment set-up to elevation bands}

Comparable precipitation-runoff models often either use a grid-based spatial discretization (e.g. Huss et al., 2008) or an elevation band approach (e.g. Schaefli et al., 2005; Stahl et al., 2008) to account for temperature gradients as the strongest spatially variable driver. Such an approach can be assumed to yield a more reliable representation of the snow accumulation and melt processes but it necessarily leads to a description of the equivalent precipitation-runoff transformation that cannot properly account for the spatial origin of flow. We compared the performance of a model set-up where the catchment is subdivided into 10 elevation bands (Fig. 3) to the subcatchment based set-up. A look at the model performance in terms of NSE and NSE-log for both set-ups (Fig. 10, top left) demonstrates that the elevation band approach marginally outperforms the subcatchment approach for the calibration period at the daily time step. If the best 100 of these parameter sets (in terms of NSE efficiency) are applied to the hourly time step (Fig. 10, top row, centre column), the elevation band set-up does a noticeably better job. This higher performance however disappears for the validation period (Fig. 10, top right), which is a strong hint of overfitting during the calibration period, where the calibration parameters might compensate for the lack of a proper accounting for the spatial origin of flows.

This hypothesis is supported by the fact that if we use subcatchments divided into elevation bands, we obtain a consistent improvement of the discharge simulation performance at the hourly time step for the calibration and the validation period (Fig. 10, bottom row).

\section{Conclusions}

This paper presents a precipitation-runoff model that computes spatially explicit water fluxes at the ecosystem level and that can, thus, be used as a simulation tool for ecohydrologic applications requiring distributed discharge information. The model formulates the hydrologic response of a catchment as a convolution of the subcatchment-scale hydrologic flow processes with the river network, where the kernels account for the spatial arrangements of the subcatchments linked by the river network. The hydrologic response accommodates directly any direct information on observable physiographic catchment characteristics such as in-stream flow path lengths or subcatchment area as a proxy for subsurface residence time scaling. Remaining model parameters are calibrated on observed discharge. This spatially explicit parameterization confers the model transferability across timescales, as has been demonstrated in this paper based on a cryosphere-dominated catchment from the Swiss Alps where, due to the steep topography, travel times in unchannelled areas are dominating in-stream travel times. The main focus of this paper was on discharge simulation. Including appropriate formulations of subcatchment-scale mass transformation processes, the general modelling framework can be extended to transport processes.

\section{Code availability}

A fully annotated Matlab version of the model is available at www.mathworks.ch/matlabcentral/fileexchange/, together with example data and a corresponding model set-up file to illustrate the model use. 

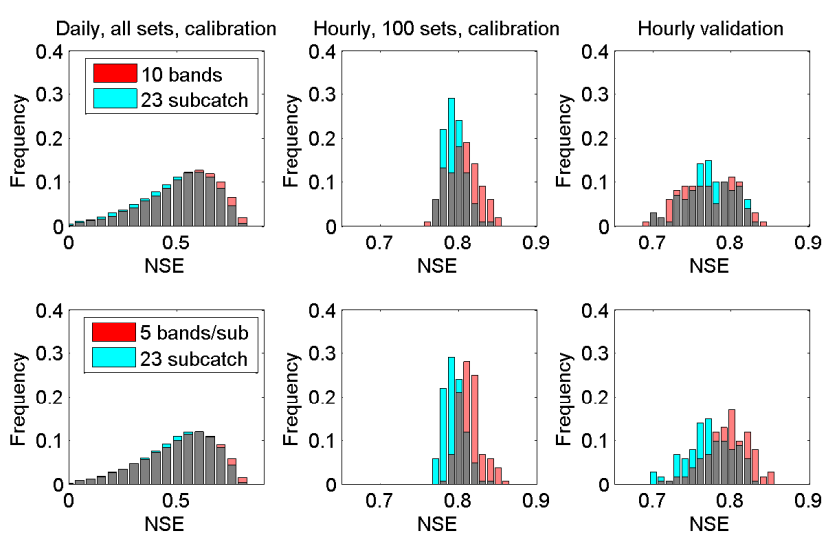

Figure 10. Comparison of model performance of the subcatchmentbased model set-up (23 subcatchments) to elevation band set-ups. Top row: comparison to 10 elevation bands (see Fig. 3), bottom row: comparison to a combination of elevation bands and subcatchments ( 5 bands for each of the 23 subcatchments). Left column: distribution of the Nash-Sutcliffe (NSE) efficiency computed at a daily time step for the calibration period (shown are parameter sets with NSE > 0); centre column: NSE distribution of the 100 sets with the highest NSE values at the daily time step run at hourly time step for the calibration period; right column: same 100 sets run at an hourly time step for the validation period. The same 35000 parameter sets are run for all three model set-ups.

\section{The Supplement related to this article is available online at doi:10.5194/gmd-7-2733-2014-supplement.}

Acknowledgements. The research of the first author of this paper has been funded through an Ambizione grant of the Swiss National Science Foundation, SNSF, number PZ00P2_147366. The last author acknowledges funding from the ERC Advanced Grant RINEC 22761 and the SNSF grant 200021_135241. The meteorological data were obtained from MeteoSwiss and the discharge data from the Swiss Federal Office for the Environment.

Edited by: R. Marsh

\section{References}

Alexander, G. N.: Effect of catchment area on flood magnitude, J. Hydrol., 16, 225-240, doi:10.1016/0022-1694(72)90054-6, 1972.

Bárdossy, A.: Calibration of hydrological model parameters for ungauged catchments, Hydrol. Earth Syst. Sci., 11, 703-710, doi:10.5194/hess-11-703-2007, 2007.

Bergström, S.: The HBV model, in: Computer Models of Watershed Hydrology, edited by: Singh, V. P., Water Resources Publications, Littleton, 443-476, 1995.

Beven, K.: Rainfall-Runoff Modelling - the Primer, 2nd Edn., Wiley-Blackwell, Oxford, 2012.
Beven, K. and Kirkby, M.: A physically based, variable contributing area model of basin hydrology, Hydrological Sciences Bulletin, 24, 43-69, 1979.

Botter, G.: Stochastic recession rates and the probabilistic structure of stream flows, Water Resour. Res., 46, W12527, doi:10.1029/2010WR009217, 2010.

Botter, G., Porporato, A., Daly, E., Rodriguez-Iturbe, I., and Rinaldo, A.: Probabilistic characterization of base flows in river basins: roles of soil, vegetation, and geomorphology, Water Resour. Res., 43, W06404, doi:10.1029/2006wr005397, 2007a.

Botter, G., Porporato, A., Rodriguez-Iturbe, I., and Rinaldo, A.: Basin-scale soil moisture dynamics and the probabilistic characterization of carrier hydrologic flows: slow, leaching-prone components of the hydrologic response, Water Resour. Res., 43, W02417, doi:10.1029/2006wr005043, 2007b.

Botter, G., Bertuzzo, E., and Rinaldo, A.: Catchment residence and travel time distributions: the master equation, Geophys. Res. Lett., 38, L11403, doi:10.1029/2011g1047666, 2011.

Boyle, D. P.: Multicriteria Calibration of Hydrological Models, Ph. D. thesis, University of Arizona, Tucson, Arizona, 2000.

Bras, R. and Rodriguez-Iturbe, I.: Random Functions and Hydrology, Addison Wesley, Reading, 1985.

Clapp, R. B. and Hornberger, G. M.: Empirical equations for some soil hydraulic-properties, Water Resour. Res., 14, 601-604, doi:10.1029/WR014i004p00601, 1978.

Clark, M. P., Rupp, D. E., Woods, R. A., Zheng, X., Ibbitt, R. P., Slater, A. G., Schmidt, J., and Uddstrom, M. J.: Hydrological data assimilation with the ensemble Kalman filter: use of streamflow observations to update states in a distributed hydrological model, Adv. Water Resour., 31, 1309-1324, doi:10.1016/j.advwatres.2008.06.005, 2008.

Comiti, F., Mao, L., Wilcox, A., Wohl, E. E., and Lenzi, M. A.: Field-derived relationships for flow velocity and resistance in high-gradient streams, J. Hydrol., 340, 48-62, doi:10.1016/j.jhydrol.2007.03.021, 2007.

Das, T., Bardossy, A., Zehe, E., and He, Y.: Comparison of conceptual model performance using different representations of spatial variability, J. Hydrol., 356, 106-118, doi:10.1016/j.jhydrol.2008.04.008, 2008.

Dingman, S.: Physical Hydrology, 2nd Edn., Prentice-Hall, Upper Saddle River, New Jersey, 2002.

Fenicia, F., Savenije, H. H. G., Matgen, P., and Pfister, L.: Is the groundwater reservoir linear? Learning from data in hydrological modelling, Hydrol. Earth Syst. Sci., 10, 139-150, doi:10.5194/hess-10-139-2006, 2006.

Formetta, G., Kampf, S. K., David, O., and Rigon, R.: Snow water equivalent modeling components in NewAge-JGrass, Geosci. Model Dev., 7, 725-736, doi:10.5194/gmd-7-725-2014, 2014.

Gelfan, A. N., Pomeroy, J. W., and Kuchment, L. S.: Modeling forest cover influences on snow accumulation, sublimation, and melt, J. Hydrometeorol., 5, 785-803, doi:10.1175/15257541(2004)005<0785: $\mathrm{mfcios}>2.0 . \mathrm{co} ; 2,2004$.

Gerrits, A. M. J., Pfister, L., and Savenije, H. H. G.: Spatial and temporal variability of canopy and forest floor interception in a beech forest, Hydrol. Process., 24, 3011-3025, doi:10.1002/hyp.7712, 2010.

Gupta, V. K., Waymire, E., and Wang, C. T.: A representation of an instantaneous unit-hydrograph from geomorphology, Water Resour. Res., 16, 855-862, doi:10.1029/WR016i005p00855, 1980. 
Heimsath, A. M., Dietrich, W. E., Nishiizumi, K., and Finkel, R. C.: The soil production function and landscape equilibrium, Nature, 388, 358-361, doi:10.1038/41056, 1997.

Hingray, B., Schaefli, B., Mezghani, A., and Hamdi, Y.: Signature-based model calibration for hydrologic prediction in mesoscale Alpine catchments, Hydrolog. Sci. J., 55, 1002-1016, doi:10.1080/02626667.2010.505572, 2010.

Hock, R.: Temperature index melt modelling in mountain areas, J. Hydrol., 282, 104-115, doi:10.1016/S0022-1694(03)00257-9, 2003

Hrachowitz, M., Savenije, H., Bogaard, T. A., Tetzlaff, D., and Soulsby, C.: What can flux tracking teach us about water age distribution patterns and their temporal dynamics?, Hydrol. Earth Syst. Sci., 17, 533-564, doi:10.5194/hess-17-533-2013, 2013.

Huss, M., Farinotti, D., Bauder, A., and Funk, M.: Modelling runoff from highly glacierized alpine drainage basins in a changing climate, Hydrol. Process., 22, 3888-3902, doi:10.1002/hyp.7055, 2008.

Huss, M., Jouvet, G., Farinotti, D., and Bauder, A.: Future highmountain hydrology: a new parameterization of glacier retreat, Hydrol. Earth Syst. Sci., 14, 815-829, doi:10.5194/hess-14-8152010, 2010.

Kokkonen, T., Koivusalo, H., Jakeman, T., and Norton, J.: Construction of a degree-day snow model in the light of the ten iterative steps in model development, in: Proceedings of the iEMSs Third Biennial Meeting: Summit on Environmental Modelling Software Society, Burlington, USA, 4452-4454, 2006.

Kunstmann, H. and Stadler, C.: High resolution distributed atmospheric-hydrological modelling for Alpine catchments, J. Hydrol., 314, 105-124, doi:10.1016/j.jhydrol.2005.03.033, 2005.

Laio, F., Porporato, A., Ridolfi, L., and Rodriguez-Iturbe, I.: Plants in water-controlled ecosystems: active role in hydrologic processes and response to water stress - II. Probabilistic soil moisture dynamics, Adv. Water Resour., 24, 707-723, doi:10.1016/s0309-1708(01)00005-7, 2001.

Liu, Z. and Todini, E.: Towards a comprehensive physically-based rainfall-runoff model, Hydrol. Earth Syst. Sci., 6, 859-881, doi:10.5194/hess-6-859-2002, 2002.

Maidment, D. R. (Ed.): Handbook of Hydrology, McGraw-Hill, New York, 1993.

McDonnell, J., Sivapalan, M., Vaché, K., Dunn, S., Grant, G., Haggerty, R., Hinz, C., Hooper, R., Kirchner, K., Roderick, M. L., Selker, J., and Weiler, M.: Moving beyond heterogeneity and process complexity: a new vision for watershed hydrology, Water Resour. Res., 43, W07301, doi:10.1029/2006WR005467, 2007.

McDonnell, J. J., McGuire, K., Aggarwal, P., Beven, K. J., Biondi, D., Destouni, G., Dunn, S., James, A., Kirchner, J., Kraft, P., Lyon, S., Maloszewski, P., Newman, B., Pfister, L., Rinaldo, A., Rodhe, A., Sayama, T., Seibert, J., Solomon, K., Soulsby, C., Stewart, M., Tetzlaff, D., Tobin, C., Troch, P., Weiler, M., Western, A., Wörman, A., and Wrede, S.: How old is streamwater? Open questions in catchment transit time conceptualization, modelling and analysis, Hydrol. Process., 24, 1745-1754, doi:10.1002/hyp.7796, 2010.

Menzel, L., Lang, H., and Rohmann, M.: Mean annual actual evaporation 1973-1992, in: Hydrological Atlas of Switzerland, Plate 4.1, Service Hydrologique et Géologique National, Bern, 1999.
Merz, R. and Blöschl, G.: Regionalisation of catchment model parameters, J. Hydrol., 287, 95-123, 2004.

Moradkhani, H., Hsu, K.-L., Gupta, H., and Sorooshian, S.: Uncertainty assessment of hydrologic model states and parameters: sequential data assimilation using the particle filter, Water Resour. Res., 41, W05012, doi:10.1029/2004WR003604, 2005.

Nash, J. E. and Sutcliffe, J. V.: River flow forecasting through conceptual models. Part I, a discussion of principles, J. Hydrol., 10, 282-290, doi:10.1016/0022-1694(70)90255-6, 1970.

Nicótina, L., Alessi Celegon, E., Rinaldo, A., and Marani, M.: On the impact of rainfall patterns on the hydrologic response, Water Resour. Res., 44, W12401, doi:10.1029/2007WR006654, 2008.

Nicótina, L., Tarboton, D., Tesfa, T., and Rinaldo, A.: Hydrologic controls on equilibrium soil depths, Water Resour. Res., 47, W04517, doi:10.1029/2010WR009538, 2011.

Perrin, C., Michel, C., and Andreassian, V.: Improvement of a parsimonious model for streamflow simulation, J. Hydrol., 279, 275-289, 2003.

Pilgrim, D. H., Cordery, I., and Baron, B. C.: Effects of catchment size on runoff relationships, J. Hydrol., 58, 205-221, doi:10.1016/0022-1694(82)90035-X, 1982.

Pomeroy, J. W., Gray, D. M., Shook, K. R., Toth, B., Essery, R. L. H., Pietroniro, A., and Hedstrom, N.: An evaluation of snow accumulation and ablation processes for land surface modelling, Hydrol. Process., 12, 2339-2367, 1998.

Porporato, A., Daly, E., and Rodriguez-Iturbe, I.: Soil water balance and ecosystem response to climate change, Am. Nat., 164, 625-632, doi:10.1086/424970, 2004.

Priestley, C. and Taylor, R.: On the assessment of surface heat flux and evaporation using large-scale parameters, Mon. Weather Rev., 100, 81-92, doi:10.1175/15200493(1972)100<0081:OTAOSH>2.3.CO;2, 1972.

Reed, S., Koren, V., Smith, M., Zhang, Z., Moreda, F., Seo, D.-J., and Participants, D.: Overall distributed model intercomparison project results, J. Hydrol., 298, 27-60, doi:10.1016/j.jhydrol.2004.03.031, 2004.

Rinaldo, A., Marani, M., and Rigon, R.: Geomorphological dispersion, Water Resour. Res., 27, 513-525, 1991.

Rinaldo, A., Botter, G., Bertuzzo, E., Uccelli, A., Settin, T., and Marani, M.: Transport at basin scales: 1. Theoretical framework, Hydrol. Earth Syst. Sci., 10, 19-29, doi:10.5194/hess-1019-2006, 2006.

Rodriguez-Iturbe, I. and Porporato, A.: Ecohydrology of WaterControlled Ecosystems - Soil Moisture and Plant Dynamics, Cambridge University Press, Cambridge, 15-58, 2004.

Rodriguez-Iturbe, I. and Rinaldo, A.: Fractal River Basins: Chance and Self-Organization, Cambridge University Press, New York, 1997.

Rodriguez-Iturbe, I. and Valdés, J. B.: The geomorphologic structure of hydrologic response, Water Resour. Res., 15, 1409-1420, 1979.

Rodriguez-Iturbe, I., Porporato, A., Ridolfi, L., Isham, V., and Cox, D.: Probabilistic modelling of water balance at a point: the role of climate, soil and vegetation, P. Roy. Soc. Lond. A-Math. Phy., 455, 3789-3805, 1999.

Rohrer, M. B., Braun, L. N., and Lang, H.: Long-term records of snow cover water equivalent in the Swiss Alps. 2. Simulations, Nord. Hydrol., 25, 65-78, 1994. 
Schaake, J. C., Koren, V. I., Duan, Q.-Y., Mitchell, K., and Chen, F.: Simple water balance model for estimating runoff at different spatial and temporal scales, J. Geophys. Res.-Atmos., 101, 7461-7475, doi:10.1029/95JD02892, 1996.

Schaefli, B. and Gupta, H.: Do Nash values have value?, Hydrol. Process., 21, 2075-2080, doi:10.1002/hyp.6825, 2007.

Schaefli, B. and Huss, M.: Integrating point glacier mass balance observations into hydrologic model identification, Hydrol. Earth Syst. Sci., 15, 1227-1241, doi:10.5194/hess-15-12272011, 2011.

Schaefli, B., Hingray, B., Niggli, M., and Musy, A.: A conceptual glacio-hydrological model for high mountainous catchments, Hydrol. Earth Syst. Sci., 9, 95-109, doi:10.5194/hess-9-95-2005, 2005.

Sivapalan, M., Jothityangkoon, C., and Menabde, M.: Linearity and nonlinearity of basin response as a function of scale: discussion of alternative definitions, Water Resour. Res., 38, 1012, doi:10.1029/2001wr000482, 2002.

Stahl, K., Moore, R., Shea, J., Hutchinson, D., and Cannon, A.: Coupled modelling of glacier and streamflow response to future climate scenarios, Water Resour. Res., 44, W02422, doi:10.1029/2007WR005956, 2008.

Swiss Federal Office for Statistics: Geostat - Version 1997, Swiss Spatial Land Use Statistics Database, Bern, Switzerland, 2001.

SwissTopo: DHM25 - the Digital Height Model of Switzerland, available at: http://www.swisstopo.admin.ch/internet/swisstopo/ en/home/products/height/dhm25.html (last access: November 2014), 2005.

SwissTopo: Vector25 - the Digital Landscape Model of Switzerland, available at: http://www.swisstopo.admin.ch/internet/ swisstopo/en/home/products/landscape/vector25.html (last access: November 2014) 2008.

Tague, C. L. and Band, L. E.: Evaluating explicit and implicit routing for watershed hydro-ecological models of forest hydrology at the small catchment scale, Hydrol. Process., 15, 1415-1439, doi:10.1002/hyp.171, 2001.

Tarboton, D. G.: A new method for the determination of flow directions and upslope areas in grid digital elevation models, Water Resour. Res., 33, 309-319, doi:10.1029/96wr03137, 1997.
Tobin, C., Nicótina, L., Parlange, M. B., Berne, A., and Rinaldo, A.: Improved interpolation of meteorological forcings for hydrologic applications in a Swiss Alpine region, J. Hydrol., 401, 77-89, doi:10.1016/j.jhydrol.2011.02.010, 2011.

Tobin, C., Rinaldo, A., and Schaefli, B.: Snowfall limit forecasts and hydrological modeling, J. Hydrometeorol., 13, 1507-1519, 2012.

Tobin, C., Schaefli, B., Nicótina, L., Simoni, S., Barrenetxea, G., Smith, R., Parlange, M., and Rinaldo, A.: Improving the degreeday method for sub-daily melt simulations with physicallybased diurnal variations, Adv. Water Resour., 55, 149-164, doi:10.1016/j.advwatres.2012.08.008, 2013.

Verbunt, M., Gurtz, J., Jasper, K., Lang, H., Warmerdam, P., and Zappa, M.: The hydrological role of snow and glaciers in alpine river basins and their distributed modeling, J. Hydrol., 282, 36-55, 2003.

Viviroli, D., Zappa, M., Schwanbeck, J., Gurtz, J., and Weingartner, R.: Continuous simulation for flood estimation in ungauged mesoscale catchments of Switzerland - Part I: Modelling framework and calibration results, J. Hydrol., 377, 191-207, doi:10.1016/j.jhydrol.2009.08.023, 2009.

Vrugt, J. A., Gupta, H. V., Bouten, W., and Sorooshian, S.: A shuffled complex evolution Metropolis algorithm for optimization and uncertainty assessment of hydrologic models, Water Resour. Res., 39, 1201, doi:10.1029/2002WR001642, 2003.

Vrugt, J., ter Braak, C., Diks, C., Higdon, D., Robinson, B., and Hyman, J.: Accelerating Markov chain Monte Carlo simulation by differential evolution with self-adaptive randomized subspace sampling, Int. J. Nonlinear Sci., 10, 273-290, 2009.

Wigmosta, M. S., Vail, L. W., and Lettenmaier, D. P.: A distributed hydrology-vegetation model for complex terrain, Water Resour. Res., 30, 1665-1679, doi:10.1029/94wr00436, 1994.

Wrede, S., Seibert, J., and Uhlenbrook, S.: Distributed conceptual modelling in a Swedish lowland catchment: a multicriteria model assessment, Hydrol. Res., 44, 318-333, doi:10.2166/nh.2012.056, 2013.

Yochum, S. E., Bledsoe, B. P., David, G. C. L., and Wohl, E.: Velocity prediction in high-gradient channels, J. Hydrol., 424-425, 84-98, doi:10.1016/j.jhydrol.2011.12.031, 2012. 